Journal of Chromatography, 168 (1979) 550-556

(C) Elsevier Scientific Publishing Company, Amsterdam - Printed in The Netherlands

CHROM. 11,375

\title{
Note
}

\section{Determination of lysinoalanine by densitometry}

\author{
N. HAAGSMA and B. G. M. GORTEMAKER
}

University of Utrecht, Faculty of Veterinary Medicine, Department of Food Chemistry, Utrechtseweg 48, 3704 HE Zeist (The Netherlands)

(Received July 10th, 1978)

Lysinoalanine (LAL), the trivial name of $\mathrm{N}^{\varepsilon}$-(DL-2-amino-2-carboxyethyl)-Llysine, is an amino acid which can arise in food proteins from lysyl and seryl residues ${ }^{1,2}$. This compound has recently attracted considerable attention because of its ability to induce renal lesions in rats ${ }^{3-5}$. In most studies on LAL, this compound was determined by means of an amino acid analyzer ${ }^{1,3,5,6}$. Recently, however, Sternberg et al. ${ }^{7}$ have described a method consisting of thin-layer chromatography (TLC) and densitometry.

This note describes our experience with this method, in particular the protein hydrolysis, the chromatographic procedure and the colouring with ninhydrin.

\section{MATERIALS AND METHODS}

\section{Amino acids}

Lysinoalanine, ornithinoalanine [ $\mathrm{N}^{\delta}$-(DL-2-amino-2-carboxyethyl)-L-ornithine, $\mathrm{OAL}]$ and lysinomethylalanine [NE-(DL-1-methyl-2-amino-2-carboxyethyl)-I-lysine, LAL (Me)] were synthesized by the Central Institute for Nutrition and Food Research TNO, according to the method of Okudo and $\mathrm{Zahn}^{8}$. S- $\beta$-(4-Pyridylethyl)-L-cysteine (PEC) was also synthesized by the same Institute according to the method of Cavins and Friedman?. The following amino acids were purchased: $\mathrm{AA}_{5}$ standard amino acid solution (Calbiochem, Los Angeles, Calif., U.S.A.), containing lysine, histidine, arginine, threonine, serine, glutamic acid, proline, glycine, alanine, cystine, valine, methionine, isoleucine, leucine, tyrosine and phenylalanine; lanthionine, DLand meso-' orms (Nutritional Biochemical Corp., Cieveland, Ohio, U.S.A.); mixed DL- and DL-allo- $\delta$-hydroxylysine hydrochloride (Sigma, St. Louis, Mo., U.S.A.); L-ornithine monohydrochloride (Fluka, Buchs, Switzerland); DL-methioninsulphon (Fluka); DL-norleucine (Fluka); L-1-methylhistidine monohydrate (Calbiochem); L-3-methylhistidine (Calbiochem); DL-2,3-diaminopropionic acid hydrochloride (Fluka); DL-tryptophan (E. Merck, Darmstadt, G.F.R.); DL-cysteic acid (Koch-Light, Colnbrook, Great Britain); DL-y-aminobutyric acid (Hoffmann-La Roche, Basle, Switzerland); D-galactosamine hydrochloride (J. T. Baker, Phillipsburgh, N.J., U.S.A.), D-glucosamine hydrochloride (Biochem. Res. Corp., Los Angeles, Calif., U.S.A.) and N-e-methyl-L-lysine hydrochloride (Sigma). 


\section{Reagents}

Precoated cellulose layers $(0.1 \mathrm{~mm}$ thickness) were used (Macherey, Nagel \& Co., Düren, G.F.R.; Cel 300-10). The plates were densitometrically tested; plates of irregular thickness were not used. The ninhydrin solution was prepared by dissolving $1 \mathrm{~g}$ of ninhydrin in a mixture of $97 \mathrm{ml}$ of $n$-butanol and $3 \mathrm{ml}$ of glacial acetic acid. A copper sulphate solution was obtained by dissolving $2 \mathrm{mg}$ of $\mathrm{CuSO}_{4} \cdot 5 \mathrm{H}_{2} \mathrm{O}$ in $10 \mathrm{ml}$ of distilled water and then adding $30 \mathrm{ml}$ of $95 \%$ ethanol. Ninhydrin, acetic acid, copper sulphate, ethanol and $37 \%$ hydrochloric acid were purchased from E. Merck, n-butanol and formic acid from J. T. Baker. All the reagents used were analyticalreagent grade.

The samples investigated, i.e., alkali-treated soy proteins, sodium caseinate and gelatine, were commercial products.

\section{Sample preparation}

The sample ( $200-250 \mathrm{mg}$ dry weight) was hydrolyzed by boiling in $200 \mathrm{ml}$ of $6 N$ hydrochloric acid for $22 \mathrm{~h}$. The hydrolysate was evaporated to dryness in a rotary evaporator at $50^{\circ}$. The residue was redissolved in $20 \mathrm{ml}$ of water and the evaporation was repeated twice. In some cases it was necessary to filter the solution before the last evaporation. The final residue was dissolved in $10 \mathrm{ml}$ of water. This solution is suitable for chromatography. Solutions obtained from samples with a content higher than 800 ppm of LAL (on a dry weight basis) have to be diluted with water.

\section{Chromatography}

The samples were applied by repeated spotting using a 5- $\mu 1$ SGE syringe fitted with a PTFE nozzle, with the aid of a stream of warm air. The maximum allowable amount of hydrolysate per spot corresponds to $125 \mu \mathrm{g}$ dry weight of the sample. The spots should be as small as possible (diameter ca. $3 \mathrm{~mm}$ ). LAL was applied to each plate, in amounts up to $0.10 \mu \mathrm{g}$, in separate spots for calibration.

Ascending chromatography was performed ${ }^{7}$ in the solvent system $90 \%$ formic acid-n-butanol-water $(4: 23: 5)$ in an unsaturated tank (Desaga, Heidelberg, G.F.R.). The distance travelled by the solvent was $17 \mathrm{~cm}$ from the start. The development ivas performed three times, the elution time for each run being $4 \mathrm{~h}$.

\section{Measurements of spots}

After drying the developed plate for $0.5 \mathrm{~h}$ at room temperature, it was sprayed with the ninhydrin solution and dried for $10 \mathrm{~min}$ at $110^{\circ}$. The layer was sprayed subsequently with the copper sulphate solution and dried for $30 \mathrm{~min}$ at room temperature. The spots were scanned with a Vitatron TLD 100 densitometer (Vitatron, Dieren, The Netherlands) connected to a Vitratron UR 402 integrating recorder. The operating conditions were: transmittance mode $\log (-)$; filter, $525 \mathrm{~nm}$; level d; diaphragm, $0.25 \mathrm{~mm}$; stroke distance, $5 \mathrm{~mm}$; scan speed, $3 \mathrm{~cm} / \mathrm{min}$; recorder chart speed, $10 \mathrm{~cm} / \mathrm{min}$; integrator 7 ; span variation from $9 / 25$ to $9 / 90$, dependent on the spot intensity and background signal of the sample. Peak areas were calculated by means of the integrator readings and corrected for fluctuations in the background absorption due to variations in layer thickness as indicated by the manufacturer ${ }^{10}$. The amount of LAL in each hydrolysate was calculated from the mean of three determinations made on one plate. 


\section{RESULTS AND DISCUSSION}

\section{Hydrolysis}

Protein hydrolysis can be carried out in sealed tubes or under total refiux. We think the sealed-tube technique is less convenient for routine determinations than the open-flask hydrolysis under total reflux. Moreover, disadvantage of the sealedtube technique is the limited sample size, which may result, in some cases, in samples which are not representative of the material investigated. Both the sealed-tube method, followed by removal of the bulk of $\mathrm{HCl}$ in a desiccator over $\mathrm{NaOH}$ as used by Sternberg, and the open-fiask hydrolysis were applied to three samples, i.e., alkalitreated casein, a commercial product containing a whipping agent and alkali-treated soy proteir. Differences in chromatographic separation were not observed. Slump ${ }^{6}$ has already demonstrated that, for most proteins, hydrolysis in $6 N$ hydrochloric acid for $22 \mathrm{~h}$ under total reflux is sufficient for complete liberation of LAL.

\section{Chromatography}

A prerequisite for densitometry is the complete separation of the given compound from interfering substances. In this respect, both Eastman cellulose sheets (catalogue number 13255) used by Sternberg et al. and the plates of Macherey, Nagel \& Co. (MN), which we used, were suitable. However, in the case of MN plates, the $R_{F}$ value of LAL is somewhat larger, and LAL is further removed from other ninhydrin-positive substances, resulting in a better chromatogram. Moreover, we found that MN cellulose plates were in general more homogeneous than Eastman sheets, which results in a lower background noise. An example of a densitogram, showing the results of LAL determinations on MN plates and on Eastman sheets, is provided in Fig. 1.

Not all types of cellulose plates are suitable for separation: it was found, that under the same chromatographic conditions, LAL interferes with other ninhydrinpositive substances, i.e., lanthionine and cysteic acid, when Eastman cellulose sheets containing a fluorescence indicator (catalogue number 13254) were used. Precoated cellulose layers of Merck (catalogue number 5716) are also unsuitable. The Gelman chamber applied by Sternberg is not essential for LAL separation.

The method was also tested on ornithinoalanine (OAL), a compound which, like LAL, may arise during alkali treatment of proteins ${ }^{11}$. It was observed that, on the Eastman sheet as well as on the MN plate, the spots of both compounds coincide. However, in alkali-treated products (i.e., soy proteins, caseinates and foaming agents), investigated on an amino acid analyzer, OAL was found to be absent or present only in negligible amounts ${ }^{12}$. If the presence of both OAL and LAL has still to be demonstrated, the ratio of the solvent components should be changed to $4: 23: 4$. This system was not investigated further.

LAL (Me), an amino acid which theoretically can be formed from threonyl and lysyl residues ${ }^{6}$, shows a slightly higher $R_{F}$ value than LAL. Furosine and pyridosine, compounds arising in acid hydrolysates of heated, proteinaceous products rich in reducing sugars, were also tested for their possible interference with the LAL determination. A hydrolysate of a lactose-hydrolyzed skimmed milk powder, in which the presence of both furosine and pyridosine was demonstrated by an amino acid 


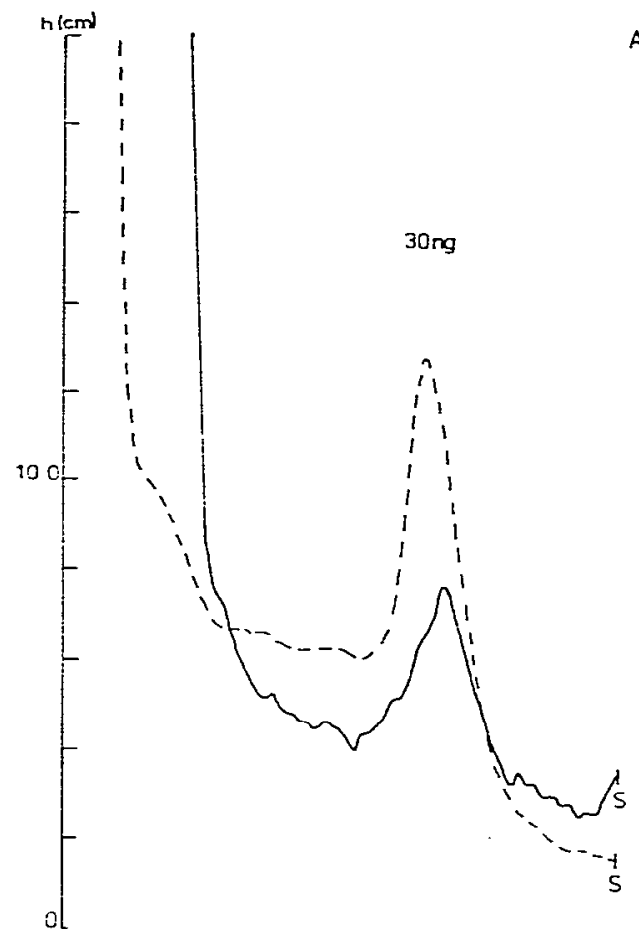

B

Fig. 1. Densitograms, showing LAL determinations on MN cellulose plates (-- ) and on Eastman cellulose sheets $(\longrightarrow)$. $A=$ Calcium caseinate $(270 \mathrm{ppm} \mathrm{LAL}) ; \mathrm{B}=$ sodium caseinate $(340 \mathrm{ppm}$ LAL); $\mathbf{S}=$ start.

analyzer, was submitted to chromatography. No ninhydrin-positive compound was found with a $R_{F}$ value equal to that of tine I.AL spot.

$\Lambda$ complete chromatogram showing the tested amino acids and some samples is shown in Fig. 2. The $R_{F}$ value of LAL in a sample was slightly lower than that of reference LAL.

Precoated silica gel plates (E. Merck, silica gel $60 \mathrm{~F}_{254}$; catalogue number 5715 ; thickness $0.25 \mathrm{~mm}$ ) were also investigated because of their better homogeneity as compared to cellulose plates. The eluent was $n$-butanol-isopropanol-acetic acidwater (4:4:4:5). After prewashing the plates with the eluent, ascending chromatography was performed for $16 \mathrm{~h}$. Ninhydrin colouring was carried out as described above (absorbance maximum, $497 \mathrm{~nm}$ ). LAL was separated from most other amino acids usually present in protein hydrolysates, with the exception of OAL, LAL (Me), 3-methylhistidine and $\mathrm{N}-\varepsilon$-methyllysine. However, colour development is much poorer compared to that on the cellulose layer, resulting in a detection limit four times that observed on cellulose. The colour is also less stable. On other silica gel plates (Woelm silica gel $F_{254 / 366}$; Macherey, Nagel \& Co. silica gel N-HR/UV 254; ; Bakerflex IB-F and Merck silica gel 60 without fluorescence indicator) LAL was not separated from one of the amino acids of the standard amino acid mixture, under the same chromatographic conditions. 


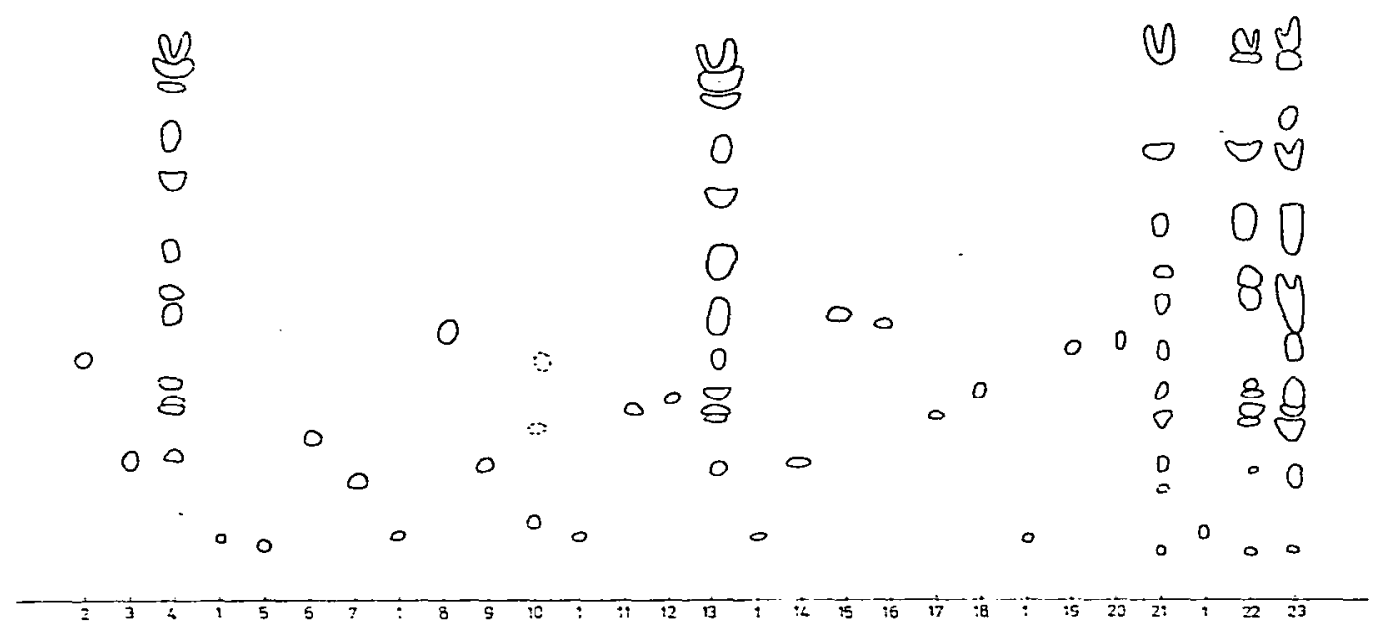

Fig. 2. Thin-layer chromatogram of amino acids on MN cellulose plates. Spots: $1=\mathrm{LAL} ; 2=$ PEC; $3=$ hydroxylysine: $4=$ standard amino acid mixture; $5=$ OAL: $6=$ ornithine: $7=$ lanthionine; $8=\gamma$-aminobutyric acid; $9=2,3$-diaminopropionic acid; $10=$ LAL(Me); $11=$ galactosamine; 12 = glucosamine: $13=$ lactose-hydrolyzed skimmed milk powder: $14=$ cysteic acid; $15=$ methioninsulphon; $16=$ tryptophan; $17=1$-methylhistidine: $18=3$-methylhistidine; $19=\mathrm{N}-\varepsilon$ methyl-L-lysine; $20=$ norleucine: $21=$ alkali-treated soy protein $(2800 \mathrm{ppm}$ LAL $) ; 22=$ sodium caseinate (550 ppm LAL): $23=$ alkali-treated soy protein ( $40 \mathrm{ppm}$ LAL).

\section{Conditions for ninhydrin spraling}

A comparison of different ninhydrin reagents demonstrated that the optimal colour intensity and stability was attained by spraying with $1 \%$ ninhydrin solution followed by spraying with copper sulphate solution, as described in Materials and methods. Moreover, the stancard deviation is lower than that obtained by spraying with ninhydrin alone. The copper sulphate spray shifts the colour maximum from 550 to $525 \mathrm{~nm}$. Spraying with a mixture of ninhydrin and copper sulphate results in a very poor colour formation. For the LAL concentrations investigated, spraying a few days after elution resulted in no colour formation. When this is the case, a good colour can still be obtained by spraying with the eluent, drying in a hood for $0.5 \mathrm{~h}$ and treating with ninhydrin and copper sulphate as already described.

Some other spray reagents were investigated with the intention of improving the sensitivity of the determination. Spraying with $o$-phthalaldehyde (Fluka), recently described by Lindberg $^{13}$ as a very sensitive reagent for amino acids on thin-layer plates, does not lead to a lower detection limit for LAL as compared to spraying with ninhydrin. This is also true when spraying with fluorescamine (Hoffmann-La Roche). Applying the procedure described by Mendez and $\mathrm{Lai}^{1+4}$ to $\mathrm{LAL}$, the minimum detectable amount was $0.02 \mu \mathrm{g}$.

\section{Linearity and sensitivity}

A linear relationship exists between the amount of LAL spotted up to $0.10 \mu \mathrm{g}$ and the corresponding peak areas, the limit of detection being $0.005 \mu \mathrm{g}$ or $40 \mathrm{ppm}$ in the sample (dry weight basis). Amounts of LAL exceeding $0.10 \mu \mathrm{g}$ per spot were not tested. 
Reproducibility and comparison with the amino acid analyzer

The reproducibility of the procedure was tested with four different samples, each being hydrolyzed six times (Table I). For the same hydrolysates, LAL was also

TABLE I

COMPARISON OF RESULTS OBTAINED BY TLC DENSITOMETRY AND BY THE AMINO ACID ANALYZER (AAA)

\begin{tabular}{|c|c|c|c|c|c|}
\hline Sample & Method & $\begin{array}{l}\text { Amount of } \\
L A L(p p m)\end{array}$ & $\begin{array}{l}\text { Range } \\
\text { (ppm) }\end{array}$ & $\begin{array}{l}\text { Standard } \\
\text { deviation }\end{array}$ & $\begin{array}{l}\text { Coefficient } \\
\text { of variation } \\
\left({ }^{\circ}{ }^{\circ}\right)\end{array}$ \\
\hline \multirow[t]{2}{*}{ Alkali-treated soy protein } & TLC & 40 & $30-55$ & $10(n=6)$ & 25 \\
\hline & AAA & 140 & $125-165$ & $15(n=6)$ & 11 \\
\hline \multirow[t]{2}{*}{ Alkali-treated soy protein } & TLC & 2800 & $2550-3000$ & $220(n=6)$ & 8 \\
\hline & AAA & 3000 & $2600-3400$ & $320(n=6)$ & 11 \\
\hline \multirow[t]{2}{*}{ Sodium caseinate } & TLC & 550 & $400-650$ & $87(n=6)$ & 16 \\
\hline & AAA & 680 & $610-800$ & $81(n=6)$ & 12 \\
\hline \multirow[t]{2}{*}{ Gelatine } & TLC & 250 & $218-308$ & $39(n=6)$ & 16 \\
\hline & AAA & 165 & $148-170$ & $12(n=6)$ & 7 \\
\hline
\end{tabular}

measured by means of an amino acid analyzer according to Slump's method $A^{6}$. For both methods the standard deviation is calculated from

$$
S=\sqrt{\frac{\Sigma\left(x_{i}-\bar{x}\right)^{2}}{n-1}}
$$

and the coefficient of variation from

$$
v=\frac{S}{\bar{x}} \cdot 100 \%
$$

The comparatively large standard deviation of the densitometric method, in particular in the low concentration range, is partly due to the tailing of a ninhydrin-positive compound present in a very high concentration in comparison with. LAL, or to incomplete separation of the LAL spot from an unknown ninhydrin-positive compound. This, in some cases, makes it rather difficult to determine the area enclosed by the LAL peak. Except for alkali-treated soy protein $(2800 \mathrm{ppm})$, the results of both methods are, with respect to the products investigated, statistically different ( $t$-test; $P=95 \%$ ). Possibly, in both methods, other unknown ninhydrin-positive compounds, dependent on the sample, are co-determined. A more extensive comparison of both methods in different foods and food products will be published elsewhere ${ }^{15}$.

\section{ACKNOWLEDGEMENTS}

The authors wish to thank Dr. P. Slump of the Central Institute for Nutrition and Food Research TNO for stimulating discussions, and Dr. A. Ruiter of the University of Utrecht for critical reading of the manuscript. We also thank Mrs. R. Schreuder of the TNO Institute for carrying out the analyses with the amino acid analyzer, and Mrs. R. van Elburg for the experiments with the silica gel plates. 


\section{REFERENCES}

1 A. P. de Groot and P. Slump, J. Nutr., 98 (1969) 45.

2 M. Sternberg, C. Y. Kim and F. J. Schwende, Science, 190 (1975) 992.

3 J. C. Woodard and D. D. Short, J. Nutr., 103 (1973) 569.

4 J. C. Woodard and D. D. Short, Food Cosmet. Toxicol., 15 (1977) 117.

5 A. P. de Groot, P. Slump, L. van Beek and V. J. Feron, J. Nutr., 106 (1976) 1527.

6 P. Slump, J. Chromatogr., 135 (1977) 502.

7 M. Sternberg, C. Y. Kim and R. A. Plumkett, J. Food Sci., 40 (1975) 1168.

8 T. Okudo and H. Zahn, Chem. Ber., 98 (1965) 1164.

9 J. F. Cavins and M. Friedman, Anal. Biochem., 35 (1970) 489.

10 H. J. Koopmans, Vitatron application report TLD 100, No. 1. Vitatron. Dieren. 1970.

11 K. Ziegler, I. Melchert and C. Lürken, Nature (London), 214 (1967) 404.

12 P. Slump, Personal communication.

13 E. G. G. Lindeberg, J. Chromatogr., 117 (1976) 439.

14 E. Mendez and C. Y. Lai, Anal. Biochem., 65 (1975) 281.

15 N. Haagsma and P. Slump, Z. Lebensm.-Unters.-Forsch., 167 (1978) 238. 